\title{
Downregulation of glucose-regulated protein 78 enhances the cytotoxic effects of curcumin on human nasopharyngeal carcinoma cells
}

\author{
XIAOMING YU ${ }^{1}$, LONG SHI $^{2}$, LI YAN $^{1}$, HUI WANG $^{1}$, YAN WEN $^{1}$ and XIUPING ZHANG \\ ${ }^{1}$ Department of Ophthalmology, Shandong Provincial Third Hospital, Jinan, Shandong 250031; \\ ${ }^{2}$ Department of Ophthalmology, Qilu Hospital of Shandong University, Jinan, Shandong 250012, P.R. China
}

Received January 26, 2018; Accepted August 21, 2018

DOI: $10.3892 /$ ijmm.2018.3837

\begin{abstract}
Curcumin is a conventional Chinese medicine, which exerts a marked effect on various tumor types and suppresses tumor invasion. The present study analyzed the antineoplastic effects of curcumin on human nasopharyngeal carcinoma (NPC) cells and determined the effects of endoplasmic reticulum (ER) stress on curcumin-induced cytotoxicity. The Cell Counting Kit-8 assay examined the viability of SUNE1 and SUNE2 NPC cells. The Annexin V/propidium iodide staining technique was used to detect cell apoptosis and flow cytometry was used to examine cell cycle distribution. Western blotting and immunofluorescence were used to detect ER stress-associated molecules. Furthermore, the toxic effects of curcumin treatment alongside glucose-regulated protein 78 (GRP78) knockdown using small interfering (si)RNA, and treatment with the pan-caspase inhibitor Z-VAD-FMK and the protein kinase B (AKT) inhibitor MK-2206 were detected. The results demonstrated that curcumin markedly reduced cell viability, blocked cell cycle progression and induced apoptosis of human NPC cells. In addition, curcumin activated ER stress-associated proteins to participate in the apoptosis of human NPC cells. siRNA-induced knockdown of GRP78 may be able to strengthen the toxic effects of curcumin through mediating the AKT signaling pathway. These findings indicated that downregulation of GRP78 promoted the therapeutic effects of curcumin on NPC cells. The present study identified a potential, novel therapeutic method for the treatment of NPC.
\end{abstract}

Correspondence to: Dr Xiaoming Yu or Professor Xiuping Zhang, Department of Ophthalmology, Shandong Provincial Third Hospital, 12 Wuyingshan Middle Road, Jinan, Shandong 250031, P.R. China

E-mail: yuxm1987@163.com

E-mail: zhangxiuping1@yeah.net

Key words: curcumin, GRP78, endoplasmic reticulum stress, AKT, NPC

\section{Introduction}

Nasopharyngeal carcinoma (NPC) is the most common primary malignancy of the nasopharynx, which frequently occurs in South China and Southeast Asia (1). The main treatment strategy for NPC is a combination of radiotherapy and chemotherapy; however, due to distant metastasis and resistance to treatment, the clinical prognosis of NPC is poor (2). In addition, numerous therapeutic measures can cause serious side effects and lead to multidrug resistance (3). Therefore, it is necessary to identify a novel, safe and effective method to treat NPC. At present, for the prevention, inhibition or delay of carcinogenesis, treatment with natural, synthetic or biological chemicals is regarded as being able to induce relatively effective chemoprevention (4).

Curcumin, 1,7-bis(4-hydroxy-3-methoxyphenyl)-1,6heptadiene-3,5-dione, is present in turmeric (Curcuma longa), and has been used to treat various diseases, including allergies, coryza, cough, anorexia, rhinitis and hepatic conditions, in Asia for centuries (5). In addition, curcumin is able to suppress proliferation and promote apoptosis in various malignant diseases (6-9). However, the functions and effects of curcumin on NPC cells require further research. Some specific functions that have been detected in other tumor models include induction of apoptosis via c-Jun $\mathrm{N}$-terminal kinase and p38 mitogen-activated protein kinase signaling pathway regulation (10), endoplasmic reticulum (ER) stress (11) and autophagy (12).

The ER is an organelle, which can fold and synthesize transmembrane, intraorganellar and secretory proteins, and accumulate intracellular calcium. Disturbance of ER homeostasis leads to ER stress and the subsequent accumulation of unfolded or misfolded proteins; this is known as the unfolded protein response (UPR). The UPR induces a series of signaling pathways to maintain ER homeostasis via the upregulation of molecular chaperones that can accelerate immunoglobulin folding and protein synthesis attenuation (13). Three ER transmembrane receptors inhibit the three signaling pathways that comprise the UPR; inositol-requiring enzyme $1 \alpha$ (IRE1 $\alpha$ ), activating transcription factor 6 and eukaryotic translation initiation factor $2 \alpha$ kinase 3 (14). Initially, UPR signaling serves a crucial role in restoring ER homeostasis; however, 
continuous or prolonged UPR results in cell apoptosis via caspase-12, caspase-4 and B-cell lymphoma 2 (Bcl-2). The present study aimed to investigate the effects of the UPR on the toxic activity of curcumin on NPC cells. The effects of interference in the UPR pathway on the toxic effects of curcumin on human NPC cells were also analyzed.

\section{Materials and methods}

Cell culture. SUNE1 and SUNE2 NPC cells were purchased from the American Type Culture Collection (Manassas, VA, USA). These cells were cultured in Dulbecco's modified Eagle's medium (HyClone; GE Healthcare Life Sciences, Logan, UT, USA) or RPMI-1640 medium (Gibco; Thermo Fisher Scientific, Inc., Waltham, MA, USA) supplemented with $10 \%$ fetal bovine serum (Gibco; Thermo Fisher Scientific, Inc.), $100 \mathrm{U} / \mathrm{ml}$ penicillin, and $100 \mu \mathrm{g} / \mathrm{ml}$ streptomycin (Gibco; Thermo Fisher Scientific, Inc., Waltham, MA, USA) at $37^{\circ} \mathrm{C}$ in an atmosphere containing $95 \%$ air and $5 \% \mathrm{CO}_{2}$.

Reagents and antibodies. Curcumin, Z-VAD-FMK (Z-VAD) and MK-2206 were purchased from Sigma-Aldrich; Merck KGaA (Darmstadt, Germany). Primary antibodies against GRP78 (cat. no. ab21685), GAPDH (cat. no. ab37168), cleaved poly (ADP-ribose) polymerase (PARP; cat. no. ab32561), caspase-3 (cat. no. ab90437), caspase-9 (cat. no. ab25758) and caspase-12 (cat. no. ab62484) were obtained from Abcam (Cambridge, UK). Antibodies against CCAAT-enhancer-binding protein homologous protein (CHOP; cat. no. 2895), IRE1 (cat. no. 3294), phosphorylated (p)-eukaryotic initiation factor $2 \alpha$ (eIF2 $\alpha$; cat. no. 9721), Bcl-2 (cat. no. 2872), protein kinase B (AKT; cat. no. 9272) and p-AKT (Ser473) (cat. no. 9271) were purchased from Cell Signaling Technology, Inc. (Danvers, MA, USA).

Measurement of cell viability. Cell viability was analyzed using the Cell Counting Kit-8 (CCK-8; Dojindo Molecular Technologies, Inc., Kumamoto, Japan). Initially, cells $\left(5 \times 10^{3} /\right.$ well $)$ were cultured in culture medium and were inoculated into 96-well plates. After 24 h, 0, 10, 20, 40 and $80 \mu \mathrm{M}$ curcumin was added to each well and the cells were cultured at $37^{\circ} \mathrm{C}$ for a further $24 \mathrm{~h}$. The original culture medium was replaced with a mixture of fresh medium and CCK-8 solution $(10 \mu \mathrm{l})$. The optical density (OD) index of the cells was measured at $450 \mathrm{~nm}$ after culturing at $37^{\circ} \mathrm{C}$ for $2 \mathrm{~h}$. The percentage of inhibition of cell activity was calculated according to the following formula: (control OD value-experiment OD value)/control group OD value x $100 \%$.

Cell cycle analysis by flow cytometry. Human NPC cells were cultured in the aforementioned culture medium. Subsequently, once the cells reached $50 \%$ confluence, they were treated with $80 \mu \mathrm{M}$ curcumin at $37^{\circ} \mathrm{C}$ for $24 \mathrm{~h}$ and were collected in order to analyze the cell cycle. Briefly, $5 \times 10^{4}$ cells were incubated with DAPI and RNase A (Thermo Fisher Scientific, Inc.) for $30 \mathrm{~min}$ at room temperature, and the cells were then suspended in $0.5 \mathrm{ml}$ propidium iodide (PI; BD Biosciences, San Jose, CA, USA) solution and incubated for $30 \mathrm{~min}$ at room temperature in the dark, according to the manufacturer's protocol. Subsequently, cell cycle distribution was analyzed using flow cytometry [fluorescence-activated cell sorting (FACS) analysis; BD FACSDiva software v8.0.1; BD Biosciences].

Apoptotic analysis by flow cytometry. Cells (4x10 $/$ well) were seeded in the aforementioned culture medium in 6-well plates and were incubated at $37^{\circ} \mathrm{C}$ for $24 \mathrm{~h}$. Subsequently, cells were treated with fresh medium containing the required concentrations of curcumin $(0,20,40$ and $80 \mu \mathrm{M})$, or the cells were pretreated with $50 \mu \mathrm{M}$ Z-VAD, followed by treatment with or without $80 \mu \mathrm{M}$ curcumin at $37^{\circ} \mathrm{C}$ for $24 \mathrm{~h}$. Cells were then stained using the Annexin $\mathrm{V}$-fluorescein isothiocyanate (FITC) apoptosis detection kit (BD Biosciences). According to the manufacturer's protocol, cells were treated for $15 \mathrm{~min}$ with a mixture of Annexin V $(5 \mu \mathrm{l})$ and PI $(5 \mu \mathrm{l})$ at room temperature. Subsequently, the stained cells were observed by flow cytometry (FACS analysis; BD FACSDiva software v8.0.1, BD Biosciences).

Western blot analysis. Cells were treated with either curcumin $(0-80 \mu \mathrm{M})$ or MK-2206 $(5 \mu \mathrm{M})$ alone or in combination for 24 h. Alternatively, cells underwent GRP78 knockdown by transient transfection with small interfering (si)RNA (20 nM) for $24 \mathrm{~h}$, after which, the transfected NPC cells were treated with or without curcumin $(80 \mu \mathrm{M})$ in complete medium at $37^{\circ} \mathrm{C}$ for $24 \mathrm{~h}$. The cells were then lysed in cold radioimmunoprecipitation assay lysis buffer (Sigma-Aldrich; Merck KGaA) supplemented with $1 \mathrm{nM}$ phenylmethylsufonyl fluoride, and were centrifuged at $12,000 \times \mathrm{g}$ for $10 \mathrm{~min}$ at $4^{\circ} \mathrm{C}$. The concentration of proteins extracted from cells was determined using a bicinchoninic acid assay (Bio-Rad Laboratories, Inc., Hercules, CA, USA). Total proteins $(20-25 \mu \mathrm{g})$ were separated by $8-15 \%$ SDS-PAGE and transferred onto a polyvinylidene fluoride membrane (EMD Millipore, Billerica, MA, USA). The membrane was then blocked in a mixture of $5 \%$ skimmed milk and PBS containing 0.1\% Tween-20 for $2 \mathrm{~h}$ at room temperature, and was incubated with primary antibodies at $4^{\circ} \mathrm{C}$ overnight [1:1,000 dilutions for GRP78, cleaved PARP, caspase-3, caspase-9, caspase-12, CHOP, IRE1, p-eIF2 $\alpha$, Bcl-2, AKT, p-AKT (Ser473) and GAPDH]. Membranes were then incubated with horseradish peroxidase-conjugated secondary antibodies (cat. nos. 7074 and 7076; 1:2,000; Cell Signaling Technology, Inc.) for $1 \mathrm{~h}$ at room temperature, followed by visualization with enhanced chemiluminescence immunoblotting detection reagents (EMD Millipore). Protein band intensities were semi-quantified by densitometric analysis using ImageJ software 1.6.0_20 (National Institutes of Health, Bethesda, MD, USA).

Immunofluorescence assay. A total of $1 \times 10^{5}$ human NPC cells were placed in each well of 6 -well chamber slides and were treated with curcumin $(80 \mu \mathrm{M})$ at $37^{\circ} \mathrm{C}$ for $24 \mathrm{~h}$. PBS was used to wash the cells, and they were then immobilized and permeabilized with $4 \%$ paraformaldehyde and $0.1 \%$ Triton $\mathrm{X}-100$ for $15 \mathrm{~min}$ at room temperature. Immunofluorescence staining was then conducted. Initially, the processed human NPC cells were stained with primary antibodies (1:1,000 for GRP78; 1:3,000 for CHOP) for $2 \mathrm{~h}$ at room temperature, and were then cultured with secondary antibodies conjugated to Alexa Fluor 488 (green) (1:200) or Alexa Fluor 546 (red) (1:200) (cat. nos. A28175 and A-11071; Invitrogen; Thermo 
Fisher Scientific, Inc.) for detection of CHOP and GRP78 for $2 \mathrm{~h}$ at room temperature, respectively. Subsequently, the cells were stained with DAPI (Abcam). Fluorescent images of the NPC cells were captured and analyzed under a light microscope (Olympus Corporation, Tokyo, Japan).

RNA interference. GRP78-specific (cat. no. sc-29338) and non-silencing scrambled siRNA (cat. no. sc-37007) were obtained from Santa Cruz Biotechnology, Inc. (Dallas, TX, USA). According to the manufacturer's protocol, $4 \times 10^{5}$ human NPC cells/well were plated in 6-well plates and transfected with siRNAs using Lipofectamine ${ }^{\circledR} 2000$ transfection reagent (Invitrogen; Thermo Fisher Scientific, Inc.) for $24 \mathrm{~h}$. Subsequently, the transfected NPC cells were exposed to curcumin $(80 \mu \mathrm{M})$ in complete medium at $37^{\circ} \mathrm{C}$ for $24 \mathrm{~h}$.

Statistical analysis. All experiments were repeated in triplicate. Data are presented as the means \pm standard deviation. The differences among multiple groups were analyzed by one-way analysis of variance followed by Dunnett's test using SPSS software (version 17.0; SPSS, Inc., Chicago, IL, USA). $\mathrm{P}<0.05$ was considered to indicate a statically significant difference.

\section{Results}

Curcumin reduces the viability of human NPC cells. In order to investigate the role of curcumin in the survival of NPC cells in vitro, SUNE1 and SUNE2 cells were exposed to various concentrations of curcumin $(0-80 \mu \mathrm{M})$ for 1 day, and inhibition of cell proliferation was evaluated by CCK-8. As shown in Fig. 1, inhibition of NPC cell viability increased with increasing concentrations of curcumin, from $13.58 \%$ inhibition following treatment with $10 \mu \mathrm{M}$ curcumin to $40.60 \%$ inhibition following treatment with $80 \mu \mathrm{M}$ curcumin in SUNE1 cells, and from $15.16 \%$ inhibition following treatment with $10 \mu \mathrm{M}$ curcumin to $43.27 \%$ inhibition following treatment with $80 \mu \mathrm{M}$ curcumin in SUNE2 cells.

Curcumin induces NPC cell apoptosis and cell cycle arrest. In order to determine the role of curcumin in apoptotic cell death, SUNE1 and SUNE2 cells were exposed to various concentrations of curcumin $(20-80 \mu \mathrm{M})$ for $24 \mathrm{~h}$. Apoptotic cell death was analyzed using the Annexin V/PI analysis. As shown in Fig. 2A-D, early apoptosis of SUNE1 cells was markedly increased from 1.49 to $17.45 \%$ and late apoptosis of SUNE1 cells was increased from 0.72 to $21.38 \%$ following exposure to $80 \mu \mathrm{M}$ curcumin for $24 \mathrm{~h}$. In addition, early and late apoptosis increased from 1.16 to $25.12 \%$ and 2.23 to $15.93 \%$ in $80 \mu \mathrm{M}$ curcumin-treated SUNE2 cells, respectively. As shown in Fig. 2E, cell cycle distribution of curcumin-treated SUNE1 and SUNE2 cells was determined. The majority of curcumin $(80 \mu \mathrm{M})$-treated NPC cells were arrested at $\mathrm{G}_{0} / \mathrm{G}_{1}$ phase; the percentage of cells in $\mathrm{G}_{0} / \mathrm{G}_{1}$ phase was increased to 68.85 and $70.88 \%$ in SUNE1 cells and SUNE2 cells, respectively. These data indicated that curcumin can induce cell death via apoptosis.

Curcumin induces ER stress in human NPC cells. To determine the effects of curcumin on ER stress in human NPC cells,

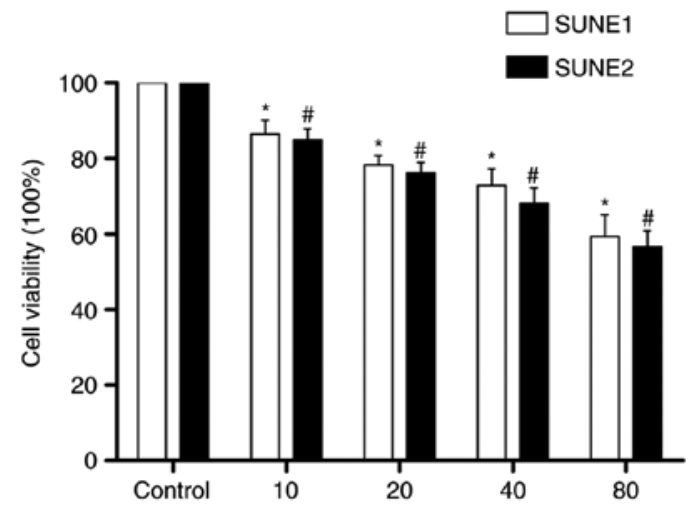

Figure 1. Effects of curcumin on the viability of human nasopharyngeal carcinoma cells. Cell viability was evaluated using the Cell Counting Kit-8 assay. SUNE1 and SUNE2 cells were exposed to curcumin for $24 \mathrm{~h}$. Data are presented as the means \pm standard deviation of three independent experiments. ${ }^{*} \mathrm{P}<0.05$ vs. the SUNE1 control group; ${ }^{\#} \mathrm{P}<0.05$ vs. the SUNE2 control group.

specific ER-associated proteins were detected. Western blot analysis demonstrated that IRE1, p-eIF $2 \alpha$, CHOP and GRP78 were increased following curcumin treatment (Fig. 3A-D). To ascertain whether curcumin can increase the expression of markers that are associated with ER stress in NPC cells, CHOP and GRP78 were analyzed by immunofluorescence staining. As shown in Fig. 3E, immunofluorescence staining of CHOP and GRP78 was markedly increased following curcumin $(80 \mu \mathrm{M})$ treatment in SUNE1 and SUNE2 cells. Previous studies have reported that prolonged ER stress can active caspase-12, and caspase-12 has an important influence on inducing cell death $(15,16)$. In order to analyze the effects of curcumin on ER stress and toxicity, and to investigate the underlying mechanisms, western blotting was used to detect the expression of the caspase-12 protein in NPC cells. As shown in Fig. 4A-D, compared with in the control group, activation of caspase-12 was increased in curcumin-treated SUNE1 and SUNE2 cells. Furthermore, the expression levels of the anti-apoptotic protein Bcl-2 were significantly decreased (Fig. 4A-D). These results indicated that ER stress may induce apoptosis.

GRP78 knockdown enhances curcumin-induced apoptosis of human NPC cells. GRP78, which is the most important marker of the UPR, has been reported to be associated with chemoresistance $(17,18)$. siRNA was used to determine the effects of GRP78 knockdown on curcumin-induced apoptosis of SUNE1 and SUNE2 cells. As shown in Fig. 5A, following GRP78 siRNA transfection, in cells that were treated with curcumin, cell viability was significantly reduced. In addition, GRP78 siRNA transfection significantly inhibited the protein expression levels of GRP78, improved PARP, caspase-3 and caspase-9 cleavage (Fig. 5B and C), and increased cell apoptosis (Fig. 6A and B) of curcumin-treated SUNE1 and SUNE2 cells. Subsequently, the pan-caspase inhibitor Z-VAD was used to investigate the role of curcumin in cell death. As shown in Fig. 6C and D, a marked reduction in cell death was detected in SUNE1 and SUNE2 cells pretreated with Z-VAD. This finding indicated that curcumin-mediated apoptosis may be associated with caspase activation. 
A
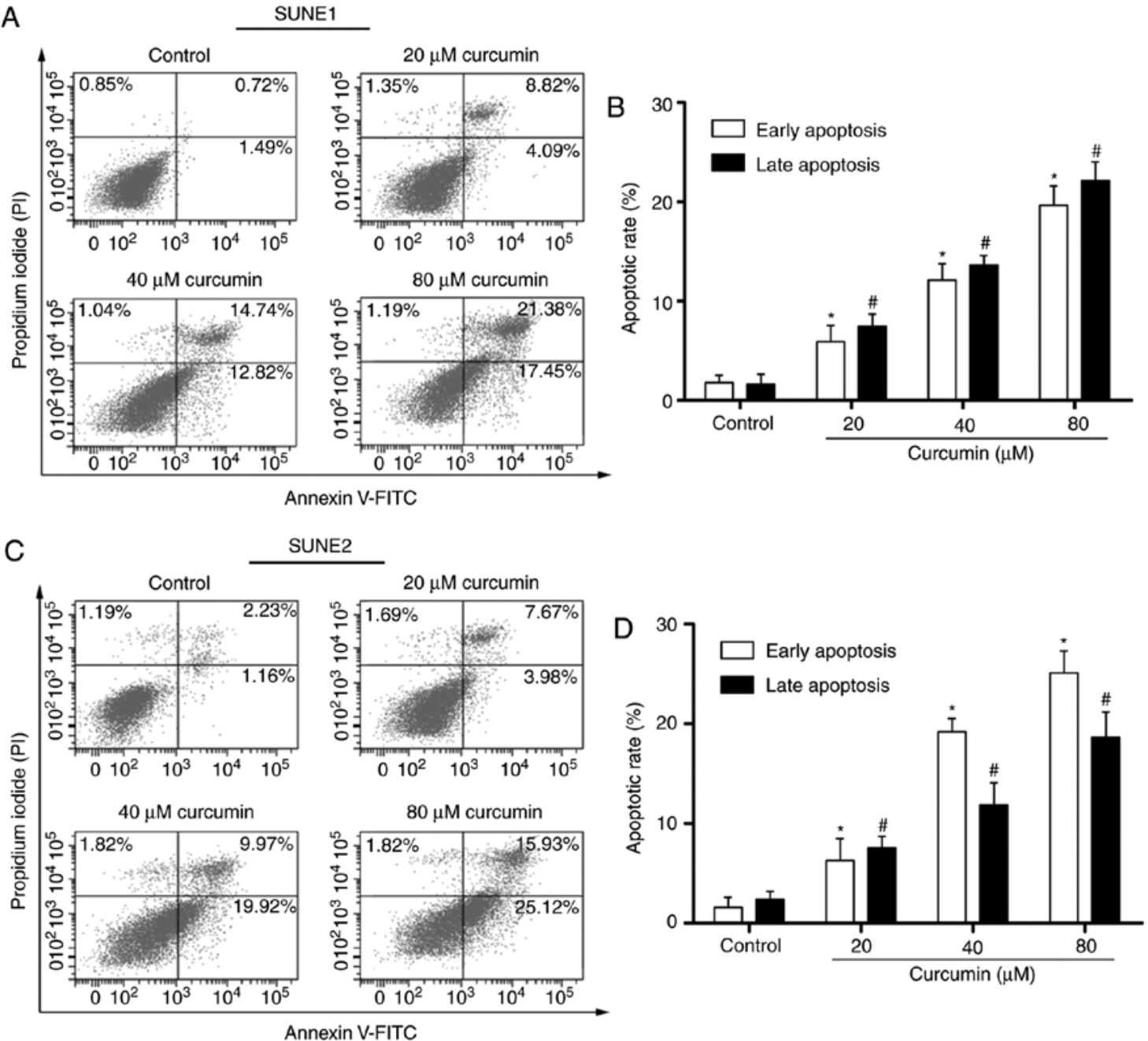

E

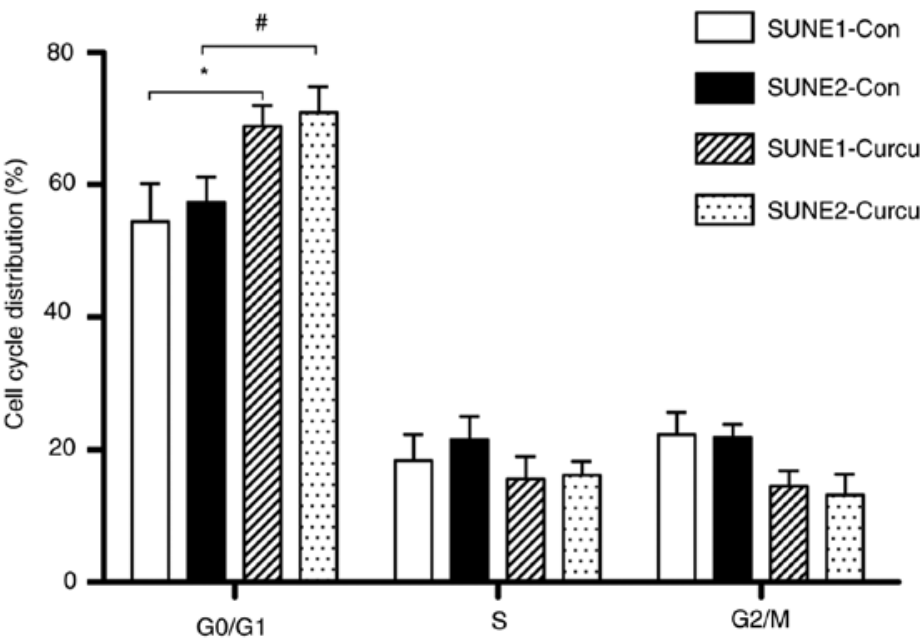

Figure 2. Effects of curcumin on cell apoptosis and cell cycle arrest of human NPC cells. (A and C) SUNE1 and SUNE2 cells were untreated (control) or treated with curcumin $(20-80 \mu \mathrm{M})$ for $24 \mathrm{~h}$. Apoptotic cells were assessed by flow cytometry using propidium iodide and Annexin V-FITC staining. (B and D) Quantitative analysis of early and late apoptotic populations. (E) Cell cycle progression of NPC cells was detected $24 \mathrm{~h}$ after treatment with curcumin $(80 \mu \mathrm{M})$. Control cells are untreated SUNE1 and SUNE2 cells. Data are presented as the means \pm standard deviation of three independent tests. ${ }^{*} \mathrm{P}<0.05$ vs. the SUNE1 control group; ${ }^{\#} \mathrm{P}<0.05$ vs. the SUNE2 control group. FITC, fluorescein isothiocyanate; NPC, nasopharyngeal carcinoma.

GRP78 knockdown reduces AKT activity in human NPC cells. The AKT pathway is important in the modification of cell growth and proliferation (19). Previous studies have reported that the GRP78 signaling pathway can regulate the AKT signaling pathway $(20,21)$. Therefore, the present study aimed to determine whether AKT was involved in GRP78-mediated cell death during curcumin treatment. As shown in Fig. 7A and B, treatment of SUNE1 and SUNE2 cells with curcumin $(80 \mu \mathrm{M})$ significantly suppressed AKT phosphorylation, whereas total AKT was only slightly altered. Knockdown 

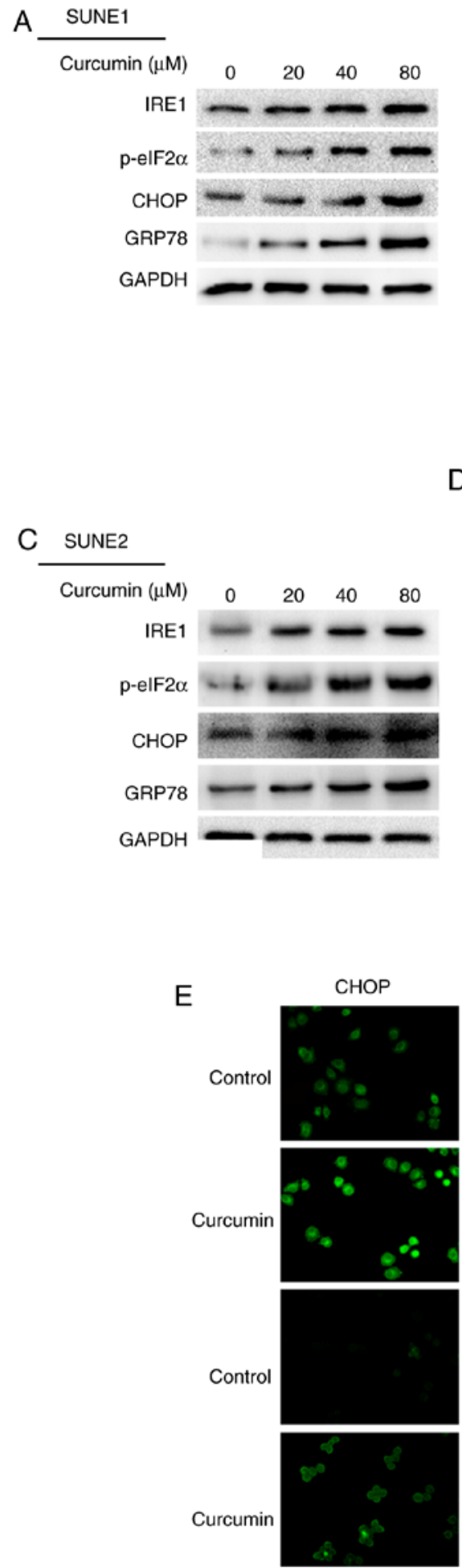
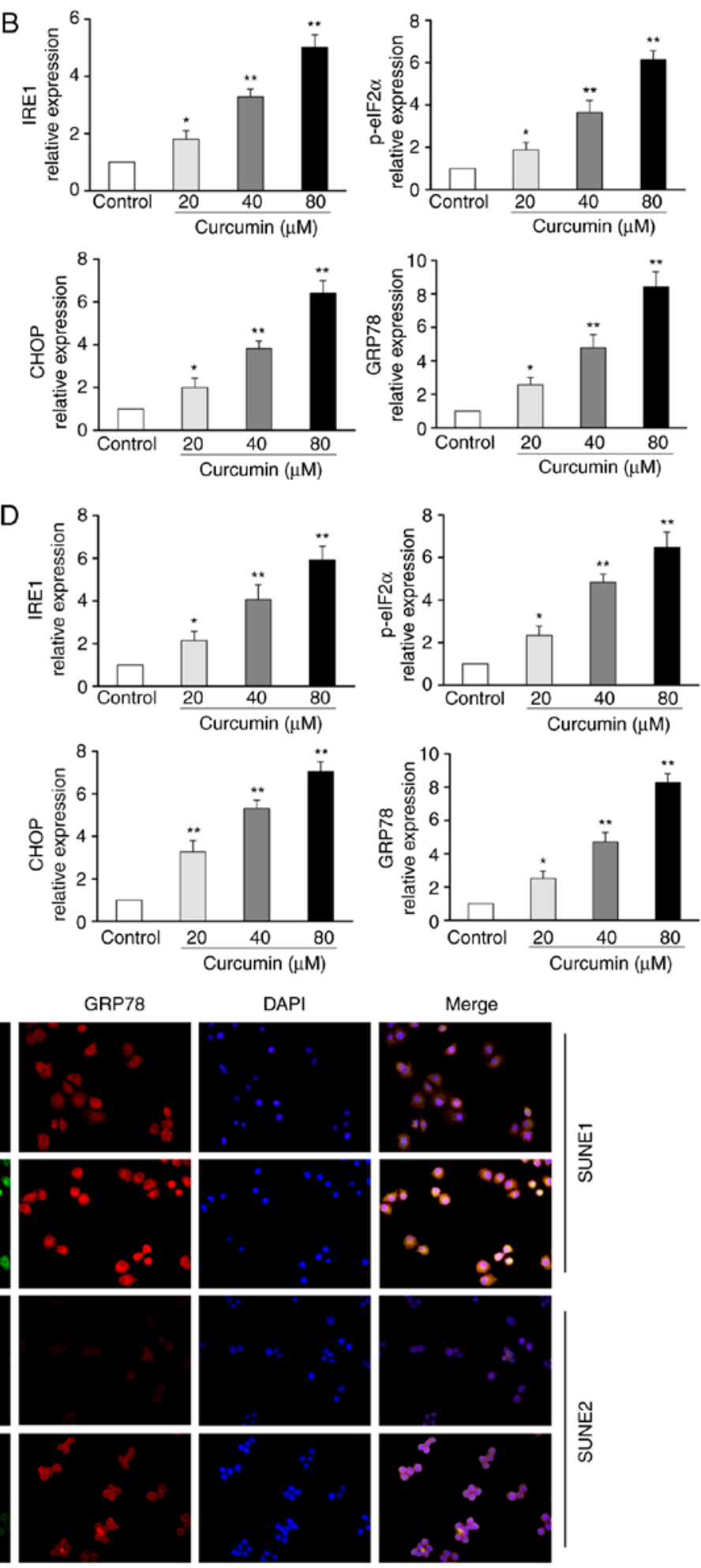

Figure 3. Effects of curcumin on ER stress-associated signaling molecules in human nasopharyngeal carcinoma cells. (A and C) Cells were untreated (control) or treated with curcumin $(20-80 \mu \mathrm{M})$ for $24 \mathrm{~h}$. To determine the expression of ER stress-associated molecules, IRE1, p-eIF2 $\alpha$, CHOP and GRP78, cell lysates were analyzed by western blotting. GAPDH was used as an internal control. The blots represent the results of at least three independent tests. (B and D) Band density in each assay was measured and normalized to that of GAPDH. ${ }^{*} \mathrm{P}<0.05$ and ${ }^{* *} \mathrm{P}<0.05$ vs. the control group. (E) Immunofluorescence analysis of CHOP (green fluorescence) and GRP78 protein (red fluorescence) (magnification, x200). CHOP, CCAAT-enhancer-binding protein homologous protein; ER, endoplasmic reticulum; GRP78, glucose-regulated protein 78; IRE1, inositol-requiring enzyme 1 ; p-eIF2 $\alpha$, phosphorylated-eukaryotic initiation factor $2 \alpha$.

of GRP78 via siRNA alongside curcumin treatment led to a marked reduction in AKT phosphorylation compared with in cells treated with curcumin only. To further investigate the effects of GRP78 expression and AKT phosphorylation,
MK-2206, a chemical inhibitor of AKT, was used to treat cells prior to treatment with curcumin. As shown in Fig. 7C and D, treating SUNE1 and SUNE2 cells with MK-2206 reduced activation of AKT. Furthermore, MK-2206 markedly 

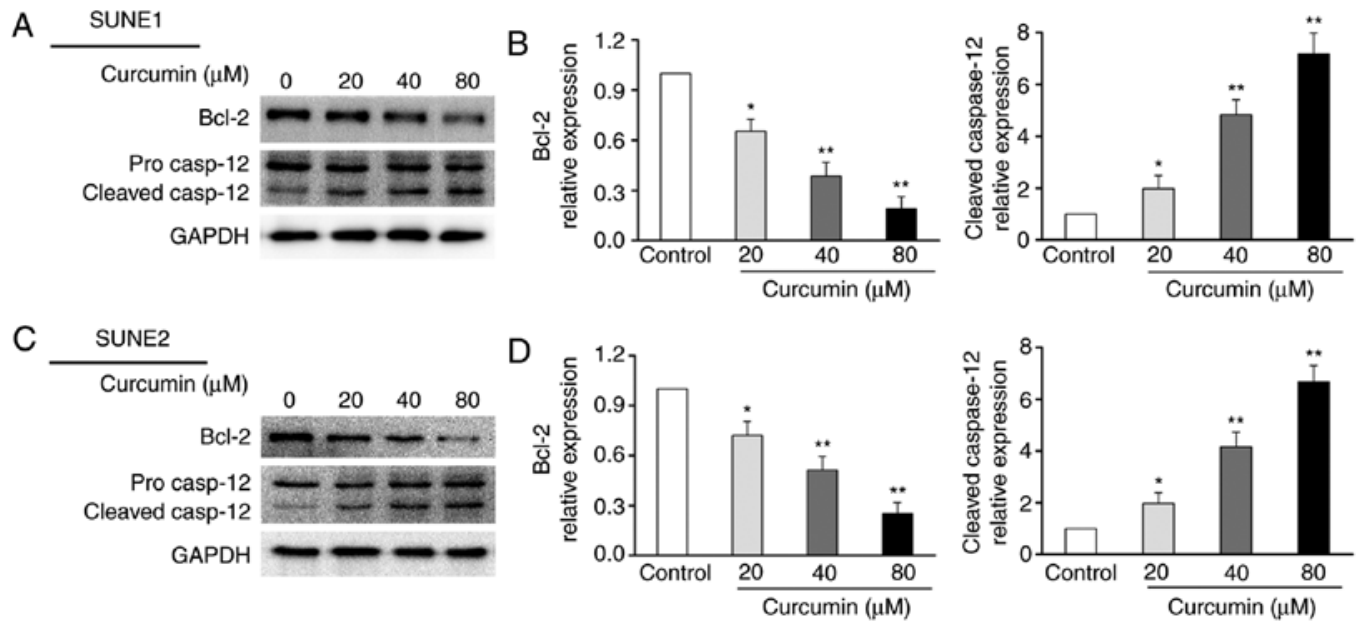

Figure 4. Effects of curcumin on the activation of caspase-12 in human nasopharyngeal carcinoma cells. (A and C) Cells were untreated (control) or treated with curcumin $(20-80 \mu \mathrm{M})$ for $24 \mathrm{~h}$. For the detection of caspase-12 and Bcl-2, cell lysates were analyzed by western blotting. GAPDH was used as an internal control. The blots represent the results of at least three independent tests. (B and D) Band density in each assay was measured and normalized to that of GAPDH. ${ }^{\mathrm{P}}<0.05$ and ${ }^{* *} \mathrm{P}<0.05$ vs. the control group. Bcl-2, B-cell lymphoma 2.

decreased the expression levels of GRP78 (Fig. 7C and D). These results indicated that GRP78 knockdown may reduce AKT activity.

\section{Discussion}

NPC is a common cancer of the nasopharynx, with a five year survival rate of $40-70 \%$ (22). Numerous patients with NPC experience recurrence or metastasis due to resistance to standard therapy with radiation (23). Therefore, it is very important to identify novel treatment modalities. Curcumin, which is a polyphenolic dienone, has been demonstrated to induce apoptosis in several human malignancies (24-27); however, the mechanisms underlying the suppressive effects of curcumin on NPC remain to be completely explored. The present study demonstrated that curcumin included ER stress, cell cycle arrest and apoptosis of human NPC cells. Knockdown of GRP78 by siRNA was able to significantly enhance curcumin-induced NPC cell apoptosis.

Previous studies have reported that ER stress is not only conducive to cell survival, but also induces apoptosis in various cell types $(28,29)$. The aim of the UPR is to reinstate appropriate ER homeostasis; however, if ER stress perseveres, the UPR signaling pathways can trigger apoptosis. Therefore, the balance between the survival signal and the apoptosis signal determines the survival and apoptosis of cells. GRP78 is an ER molecular chaperone, which is important in folding and assembling proteins (30). Previous research has indicated that constitutive overexpression of GRP78 is associated with chemoresistance in cancer treatment (31), whereas knockdown of GRP78 can enhance chemosensitivity in several tumor cells $(18,32,33)$. According to the present study, treatment of human NPC cells with curcumin led to ER stress, and curcumin-induced ER stress in SUNE1 and SUNE2 cells was associated with the upregulation of GRP78. In addition, silencing GRP78 using siRNA significantly enhanced the cytotoxic and apoptotic effects of curcumin in SUNE1 and SUNE2 cells. These data revealed that GRP78 may be crucial in protecting human NPC cells from curcumin-induced apoptosis. Therefore, downregulation of GRP78 may markedly improve the sensitivity of human NPC cells to curcumin.

Activation of the AKT signaling pathway is crucial in modifying cell proliferation and motility in various types of cancer; therefore, inhibition of AKT phosphorylation could suppress tumor cell growth and proliferation $(34,35)$. In addition, it has been demonstrated that the AKT signaling pathway is associated with chemoresistance and maintaining GRP78 expression (36,37). The present results revealed that GRP78 knockdown by siRNA significantly inhibited the phosphorylation of AKT in curcumin-treated cells. Furthermore, inhibiting AKT activity using the chemical inhibitor MK-2206 prevented curcumin-mediated GRP78 induction, and suppressed AKT activity, thus suggesting that GRP78 may function in NPC to restrict chemotherapeutic-induced cytotoxicity via regulating the AKT signaling pathway.

In conclusion, this study suggested that curcumin may inhibit the viability and promote the apoptosis of human NPC cells. Downregulation of GRP78 may further enhance curcumin-induced SUNE1 and SUNE2 cell apoptosis. These findings are promising; however, further research is required to develop novel therapeutic strategies for human NPC.

\section{Acknowledgements}

The authors would like to thank Dr. Edward C. Mignot (Shandong University, Jinan, China) for linguistic advice.

\section{Funding}

The present study was supported by the National Natural Science Foundation of China (grant no. 81400376) and thee Shandong Province Natural Science Foundation of China (grant no. BS2014YY017).

\section{Availability of data and materials}

All data generated or analyzed during this study are included in this published article. 
A
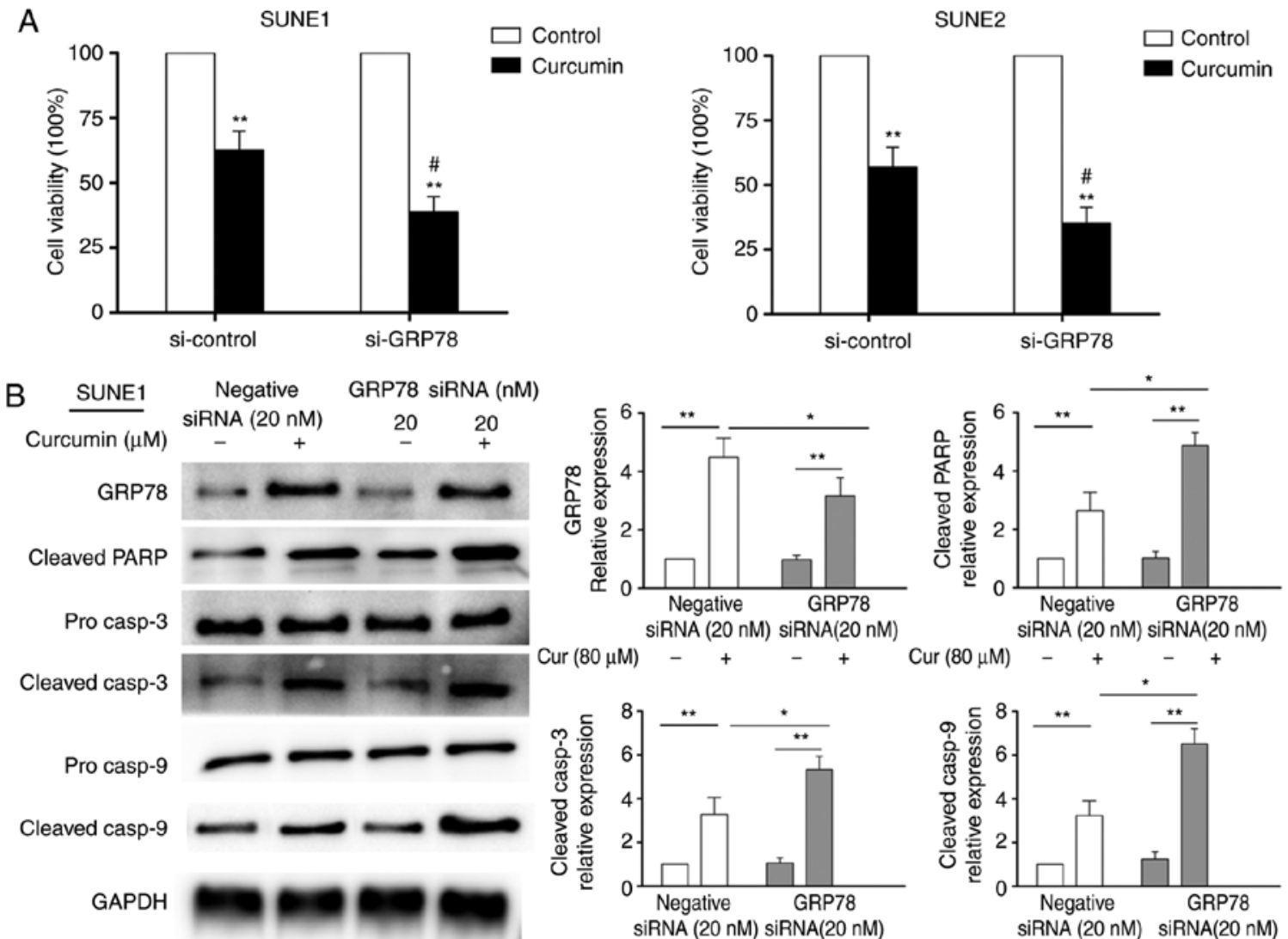

Cur $(80 \mu \mathrm{M}) \quad-\quad+\quad-$
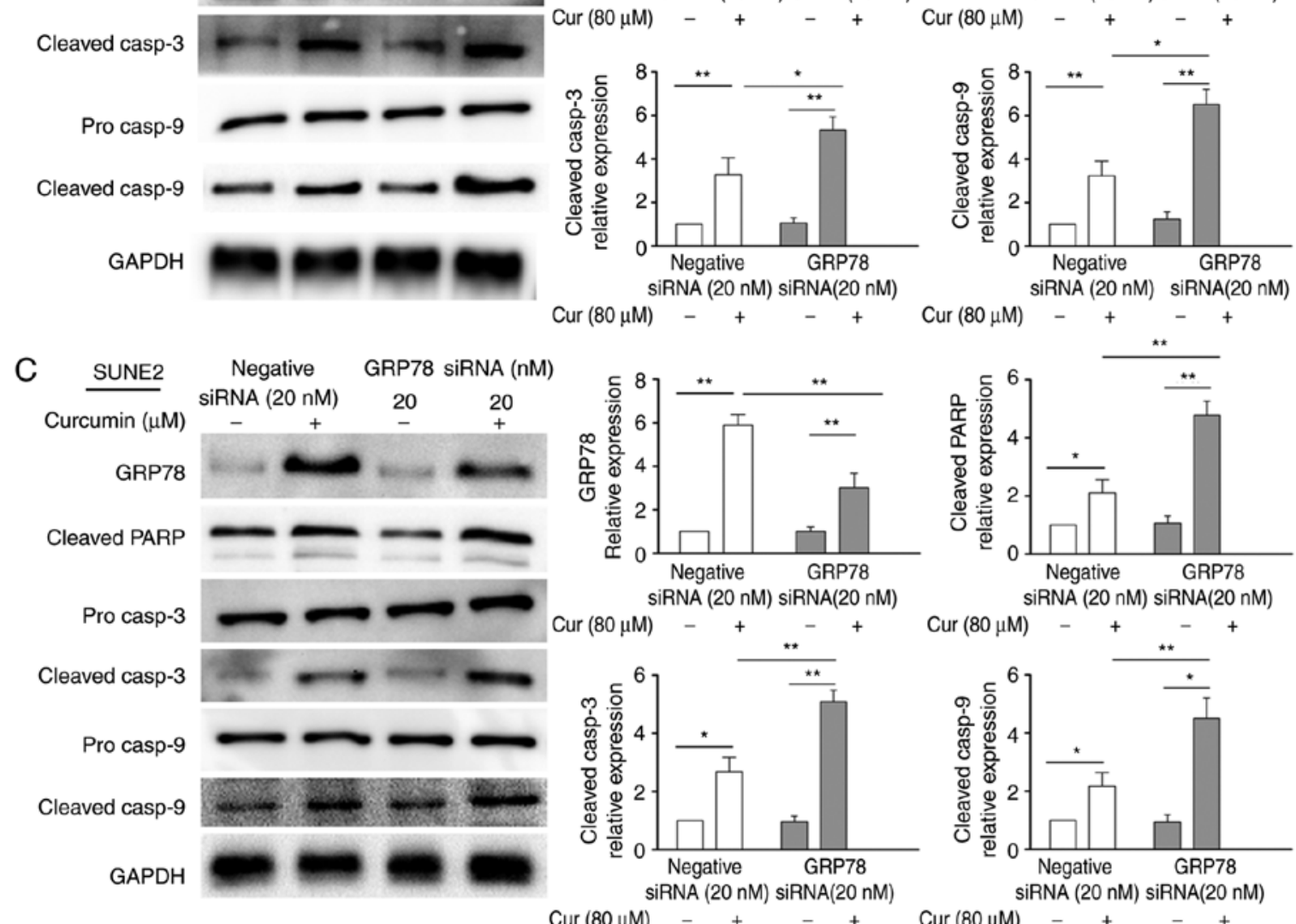

SiRNA $(20 \mathrm{nM}) \operatorname{siRNA}(20 \mathrm{nM})$

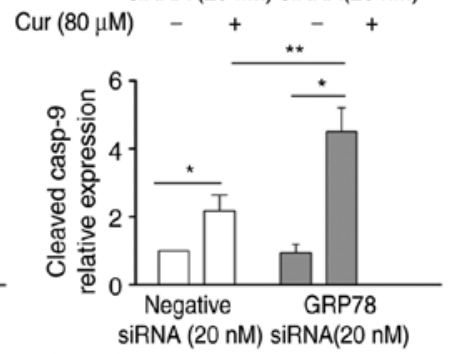

Figure 5. Knockdown of GRP78 significantly enhances the effects of curcumin on caspase and PARP activation in human nasopharyngeal carcinoma cells. (A) Cell viability was evaluated using the Cell Counting Kit-8 assay. SUNE1 and SUNE2 cells were transfected with GRP78 siRNA (20 nM) or scrambled siRNA ( $20 \mathrm{nM}$; control) and were then treated with or without curcumin $(80 \mu \mathrm{M})$ for $24 \mathrm{~h}$. Data are presented as the means \pm standard deviation of three independent tests. ${ }^{* *} \mathrm{P}<0.01$ vs. the control group, ${ }^{\#} \mathrm{P}<0.05$ vs. cells treated with curcumin only. (B and C) Cells were transfected with 20 nM GRP78 siRNA or $20 \mathrm{nM}$ scrambled siRNA (control) and were then treated with or without curcumin $(80 \mu \mathrm{M})$ for $24 \mathrm{~h}$. Protein expression levels were detected by western blotting. GAPDH was used as an internal control. The blots represent the results of at least three independent tests. Band density in each assay was measured and normalized to that of GAPDH. Data are presented as the means \pm standard deviation of three independent tests. ${ }^{*} \mathrm{P}<0.05{ }^{* * *} \mathrm{P}<0.01$. GRP78, glucose-regulated protein 78; PARP, poly (ADP-ribose) polymerase; siRNA, small interfering RNA.

\section{Authors' contributions}

$\mathrm{XY}$ performed experiments and analyzed data; XZ designed the research, interpreted data and edited the manuscript; LS wrote the manuscript and analyzed the data; LY analyzed the data and reviewed the manuscript; HW interpreted data and reviewed the manuscript; YW interpreted data and edited the manuscript. All authors read and approved the final manuscript

\section{Ethics approval and consent to participate}

Not applicable. 
A
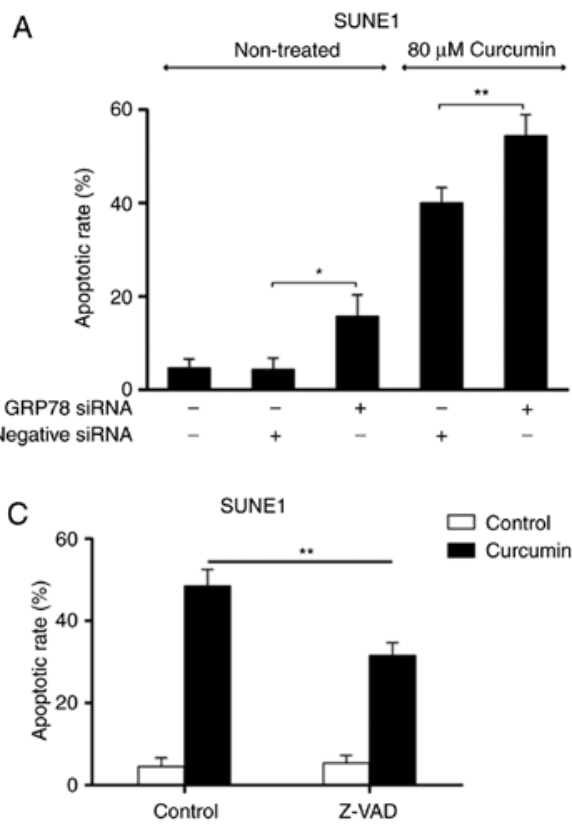

B

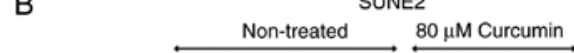

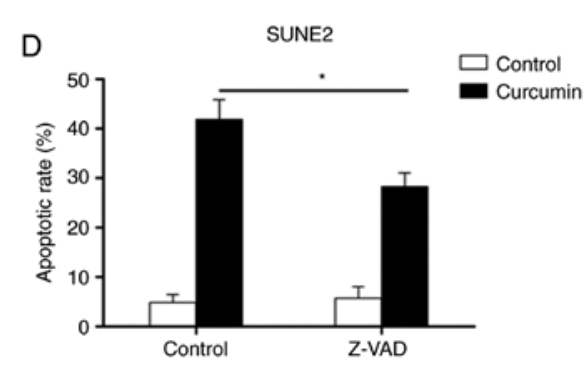

Figure 6. Downregulation of GRP78 strengthens the effects of curcumin on apoptosis of human nasopharyngeal carcinoma cells. (A and B) Flow cytometry was used to study apoptotic cells stained with PI and Annexin V-FITC. Quantitative examination of early and late apoptotic populations. (C and D) Effects of Z-VAD and curcumin on apoptosis of SUNE1 and SUNE2 cells. Following pretreatment with $50 \mu \mathrm{M} Z$-VAD, NPC cells were treated with or without $80 \mu \mathrm{M}$ curcumin. Apoptotic cells were detected by flow cytometry using PI and Annexin V-FITC staining. Data are presented as the means \pm standard deviation of three independent tests. ${ }^{*} \mathrm{P}<0.05,{ }^{* *} \mathrm{P}<0.01$. FITC, fluorescein isothiocyanate; PI, propidium iodide; siRNA, small interfering RNA; Z-VAD, Z-VAD-FMK

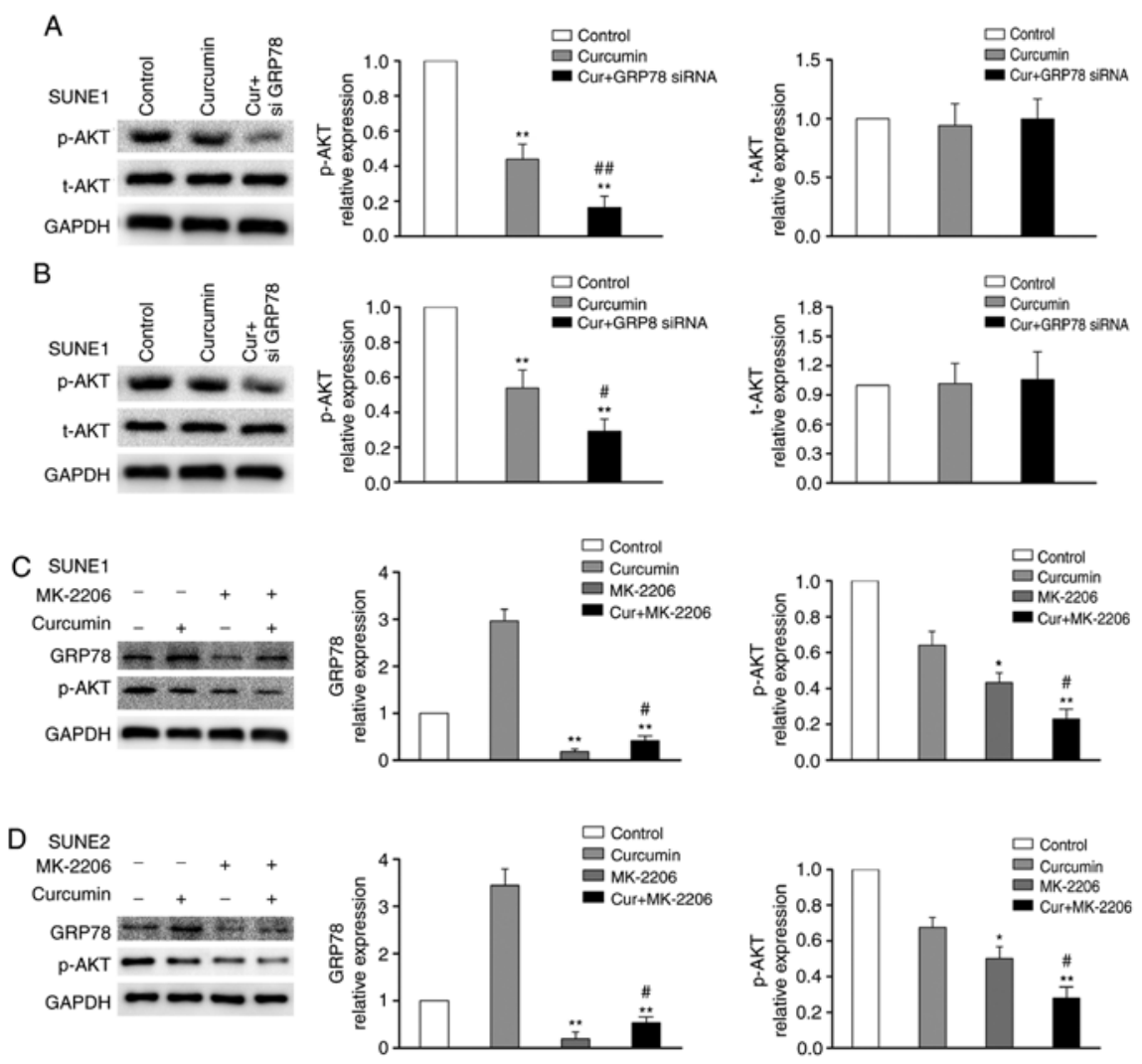

Figure 7. AKT and GRP78 signaling may have a role in human nasopharyngeal carcinoma cells, as determined by GRP78 knockdown and AKT inhibition. (A and B) GRP78 knockdown by transient transfection of siRNA $(20 \mathrm{nM})$ for $24 \mathrm{~h}$, followed by treatment with or without curcumin $(80 \mu \mathrm{M})$ and western blotting was conducted to detect p-AKT and t-AKT. GAPDH was used as an internal control. The blots represent the results of at least three independent tests. Band density in each assay was measured and normalized to that of GAPDH. Data are presented as the means \pm standard deviation of three independent tests. ${ }^{* *} \mathrm{P}<0.01$ vs. the control group; ${ }^{\#} \mathrm{P}<0.05,{ }^{\# \#} \mathrm{P}<0.01$ vs. curcumin-treated cells. (C and D) SUNE1 and SUNE2 cells were exposed to curcumin $(80 \mu \mathrm{M})$ for $24 \mathrm{~h}$ in the presence or absence of MK-2206 $(5 \mu \mathrm{M})$. GRP78 and p-AKT expression was evaluated by western blotting. GAPDH was used as an internal control. The blots represent the results of at least three independent tests. Band density in each assay was measured and normalized to that of GAPDH. Data are presented as the means \pm standard deviation of three independent tests. ${ }^{*} \mathrm{P}<0.05,{ }^{* * *} \mathrm{P}<0.01$ vs. curcumin-treated cells; ${ }^{\#} \mathrm{P}<0.05$ vs. MK-2206-treated cells. AKT, protein kinase B; GRP78, glucose-regulated protein 78; p-, phosphorylated; siRNA, small interfering RNA; t-, total. 


\section{Patient consent for publication}

Not applicable.

\section{Competing interests}

The authors declare that they have no competing interests.

\section{References}

1. Lee AW, Fee WE Jr, Ng WT and Chan LK: Nasopharyngeal carcinoma: Salvage of local recurrence. Oral Oncol 48: 768-774, 2012.

2. Xu Y, Zhang J, Shi W and Liu Y: Anticancer effects of 3,3'-diindolylmethane are associated with G1 arrest and mitochondria-dependent apoptosis in human nasopharyngeal carcinoma cells. Oncol Lett 5: 655-662, 2013.

3. Xiao WW, Huang SM, Han F, Wu SX, Lu LX, Lin CG, Deng XW, Lu TX, Cui NJ and Zhao C: Local control, survival, and late toxicities of locally advanced nasopharyngeal carcinoma treated by simultaneous modulated accelerated radiotherapy combined with cisplatin concurrent chemotherapy: Long-term results of a phase 2 study. Cancer 117: 1874-1883, 2011.

4. Huang J, Liang ZD, Wu TT, Hoque A, Chen H, Jiang Y, Zhang H and Xu XC: Tumor-suppressive effect of retinoid receptor-induced gene-1 (RRIG1) in esophageal cancer. Cancer Res 67: 1589-1593, 2007.

5. Ammon HP and Wahl MA: Pharmacology of Curcuma longa. Planta Med 57: 1-7, 1991.

6. He M, Li Y, Zhang L, Li L, Shen Y, Lin L, Zheng W, Chen L, Bian X, Ng HK and Tang L: Curcumin suppresses cell proliferation through inhibition of the Wnt/ $\beta$-catenin signaling pathway in medulloblastoma. Oncol Rep 32: 173-180, 2014

7. Qiao Q, Jiang Y and Li G: Curcumin enhances the response of non-Hodgkin's lymphoma cells to ionizing radiation through further induction of cell cycle arrest at the $\mathrm{G} 2 / \mathrm{M}$ phase and inhibition of mTOR phosphorylation. Oncol Rep 29: 380-386, 2013.

8. Du Q, Hu B, An HM, Shen KP, Xu L, Deng S and Wei MM: Synergistic anticancer effects of curcumin and resveratrol in Hepa1-6 hepatocellular carcinoma cells. Oncol Rep 29: 1851-1858, 2013.

9. Pan Y, Xiao J, Liang G, Wang M, Wang D, Wang S and Yang H: A new curcumin analogue exhibits enhanced antitumor activity in nasopharyngeal carcinoma. Oncol Rep 30: 239-245, 2013

10. Yu X, Zhong J, Yan L, Li J, Wang H, Wen Y and Zhao Y Curcumin exerts antitumor effects in retinoblastoma cells by regulating the JNK and p38 MAPK pathways. Int J Mol Med 38 $861-868,2016$.

11. Cao A, Li Q, Yin P, Dong Y, Shi H, Wang L, Ji G, Xie J and Wu D: Curcumin induces apoptosis in human gastric carcinoma AGS cells and colon carcinoma HT-29 cells through mitochondrial dysfunction and endoplasmic reticulum stress. Apoptosis 18: 1391-1402, 2013.

12. Zanotto-Filho A, Braganhol E, Klafke K, Figueiró F, Terra SR, Paludo FJ, Morrone M, Bristot IJ, Battastini AM, Forcelini CM, et al: Autophagy inhibition improves the efficacy of curcumin/temozolomide combination therapy in glioblastomas. Cancer Lett 358: 220-231, 2015.

13. Bortolozzi R, Viola G, Porcù E, Consolaro F, Marzano C, Pellei M, Gandin V and Bassoj G: A novel copper(I) complex induces ER-stress-mediated apoptosis and sensitizes B-acute lymphoblastic leukemia cells to chemotherapeutic agents. Oncotarget 5: 5978-5991, 2014.

14. Xu C, Bailly-Maitre B and Reed JC: Endoplasmic reticulum stress: Cell life and death decisions. J Clin Invest 115: 2656-2664 2005 .

15. Zhong J, Dong X, Xiu P, Wang F, Liu J, Wei H, Xu Z, Liu F, Li T and $\mathrm{Li}$ J: Blocking autophagy enhances meloxicam lethality to hepatocellular carcinoma by promotion of endoplasmic reticulum stress. Cell Prolif 48: 691-704, 2015.

16. Zhong J, Xiu P, Dong X, Wang F, Wei H, Wang X, Xu Z, Liu F, Li T, Wang Y and Li J: Meloxicam combined with sorafenib synergistically inhibits tumor growth of human hepatocellular carcinoma cells via ER stress-related apoptosis. Oncol Rep 34: 2142-2150, 2015
17. Li W, Wang W, Dong H, Li Y, Li L, Han L, Han Z, Wang S, Ma D and Wang $\mathrm{H}$ : Cisplatin-induced senescence in ovarian cancer cells is mediated by GRP78. Oncol Rep 31: 2525-2534, 2014

18. Pi L, Li X, Song Q, Shen Y, Lu X and Di B: Knockdown of glucose-regulated protein 78 abrogates chemoresistance of hypopharyngeal carcinoma cells to cisplatin induced by unfolded protein in response to severe hypoxia. Oncol Lett 7: 685-692, 2014.

19. Yip PY: Phosphatidylinositol 3-kinase-AKT-mammalian target of rapamycin (PI3K-Akt-mTOR) signaling pathway in non-small cell lung cancer. Transl Lung Cancer Res 4: 165-176, 2015.

20. Kelber JA, Panopoulos AD, Shani G, Booker EC, Belmonte JC, Vale WW and Gray PC: Blockade of Cripto binding to cell surface GRP78 inhibits oncogenic Cripto signaling via MAPK/PI3K and Smad2/3 pathways. Oncogene 28: 2324-2336, 2009.

21. Wey S, Luo B, Tseng CC, Ni M, Zhou H, Fu Y, Bhojwani D, Carroll WL and Lee AS: Inducible knockout of GRP78/BiP in the hematopoietic system suppresses Pten-null leukemogenesis and AKT oncogenic signaling. Blood 119: 817-825, 2012.

22. Zhang W, Yang P, Gao F, Yang J and Yao K: Effects of epigallocatechin gallate on the proliferation and apoptosis of the nasopharyngeal carcinoma cell line CNE2. Exp Ther Med 8: 1783-1788, 2014

23. Ma J, Wen ZS, Lin P, Wang X and Xie FY: The results and prognosis of different treatment modalities for solitary metastatic lung tumor from nasopharyngeal carcinoma: A retrospective study of 105 cases. Chin J Cancer 29: 787-795, 2010.

24. Yin H, Zhou Y, Wen C, Zhou C, Zhang W, Hu X, Wang L, You C and Shao J: Curcumin sensitizes glioblastoma to temozolomide by simultaneously generating ROS and disrupting AKT/mTOR signaling. Oncol Rep 32: 1610-1616, 2014.

25. Peng SF, Lee CY, Hour MJ, Tsai SC, Kuo DH, Chen FA, Shieh PC and Yang JS: Curcumin-loaded nanoparticles enhance apoptotic cell death of U2OS human osteosarcoma cells through the Akt-Bad signaling pathway. Int J Oncol 44: 238-246, 2014.

26. Wu J, Tang Q, Zhao S, Zheng F, Wu Y, Tang G and Hahn SS: Extracellular signal-regulated kinase signaling-mediated induction and interaction of FOXO3a and p53 contribute to the inhibition of nasopharyngeal carcinoma cell growth by curcumin. Int J Oncol 45: 95-103, 2014.

27. Yang SJ, Lee SA, Park MG, Kim JS, Yu SK, Kim CS, Kim JS, Kim SG, Oh JS, Kim HJ, et al: Induction of apoptosis by diphenyldifluoroketone in osteogenic sarcoma cells is associated with activation of caspases. Oncol Rep 31: 2286-2292, 2014.

28. Schroder M and Kaufman RJ: The mammalian unfolded protein response. Annu Rev Biochem 74: 739-789, 2005.

29. Zhang $\mathrm{K}$ and Kaufman RJ: The unfolded protein response: A stress signaling pathway critical for health and disease. Neurology 66: S102-S109, 2006.

30. Li J and Lee AS: Stress induction of GRP78/BiP and its role in cancer. Curr Mol Med 6: 45-54, 2006.

31. Lee AS: GRP78 induction in cancer: Therapeutic and prognostic implications. Cancer Res 67: 3496-3499, 2007.

32. Huang KH, Kuo KL, Chen SC, Weng TI, Chuang YT, Tsai YC, Pu YS, Chiang CK and Liu SH: Down-regulation of glucose-regulated protein (GRP) 78 potentiates cytotoxic effect of celecoxib in human urothelial carcinoma cells. PLoS One 7: e33615, 2012

33. Wang J, Yin Y, Hua H, Li M, Luo T, Xu L, Wang R, Liu D, Zhang Y and Jiang Y: Blockade of GRP78 sensitizes breast cancer cells to microtubules-interfering agents that induce the unfolded protein response. J Cell Mol Med 13: 3888-3897, 2009.

34. Singh S, Trevino J, Bora-Singhal N, Coppola D, Haura E, Altiok $S$ and Chellappan SP: EGFR/Src/Akt signaling modulates Sox 2 expression and self-renewal of stem-like side-population cells in non-small cell lung cancer. Mol Cancer 11: 73, 2012.

35. Qin J, Ji J, Deng R, Tang J, Yang F, Feng GK, Chen WD, Wu XQ, Qian XJ, Ding K and Zhu XF: DC120, a novel AKT inhibitor, preferentially suppresses nasopharyngeal carcinoma cancer stem-like cells by downregulating Sox 2 . Oncotarget 6: 6944-6958, 2015

36. Li B, Li J, Xu WW, Guan XY, Qin YR, Zhang LY, Law S, Tsao SW and Cheung AL: Suppression of esophageal tumor growth and chemoresistance by directly targeting the PI3K/AKT pathway. Oncotarget 5: 11576-11587, 2014.

37. Gray MJ, Mhawech-Fauceglia P, Yoo E, Yang W, Wu E, Lee AS and Lin YG: AKT inhibition mitigates GRP78 (glucose-regulated protein) expression and contribution to chemoresistance in endometrial cancers. Int J Cancer 133: 21-30, 2013. 